\title{
Vermelhão e Cinábrio: intercâmbios artísticos entre São Paulo e América hispânica (séculos XVI- XVIII)
}

\author{
Thais Cristina Montanari ${ }^{1}$ \\ DOI 10.20396/eha.vil4.3439
}

O sulfeto de mercúrio, dito vermelhão é um pigmento derivado do cinábrio em sua forma natural, conhecido e utilizado desde a antiguidade. Atualmente, porém, sua utilização é muito rara, devido à toxicidade do mercúrio. No Peru, por volta de 1550, o poeta e merchant português Enrique Garces reconheceu que o pó vermelho usado pelos indígenas nas pinturas corporais era cinábrio. Sabendo que o mercúrio era encontrado perto dos depósitos de cinábrio, Garces questionou os índios e soube que a fonte era próxima a Huamanga. Garces sabia que o mercúrio poderia ser utilizado no garimpo de ouro e prata, e, em 1559, obteve do Vice-rei em Lima, uma licença de 12 anos para explorar o mercúrio, tornando possível a exploração da prata de Potosí, chegando a uma escala grande e sistemática em $1572 .{ }^{2}$ Assim, além da importância para a mineração, o cinábrio, na forma de pigmento, foi largamente utilizado na pintura andina, chegando até terras paulistas no período colonial. $^{3}$

Na região da Ruta de la Plata — atual território da Bolívia e do Chile —-, ainda se preservam algumas capelas e igrejas com todo o seu interior ornamentado com pinturas murais de repertório iconográfico cristão, como o juízo final, os sacramentos, a paixão de Cristo, e a representações do céu e do inferno. ${ }^{4}$ As pinturas com padrões têxteis, brutescos e grotescas também são recorrentes, bem como a mistura destes repertórios. Assim, ao mesmo tempo em que se buscava recriar o decoro e o esplendor do interior das igrejas europeias por meio das pinturas murais, estas pinturas também eram utilizadas como ferramenta para a catequização e fixação da doutrina cristã entre os indígenas, sobretudo em localidades menos centrais onde a presença religiosa era esporádica. ${ }^{5}$

\footnotetext{
1 Mestra em História, na área de História da Arte pelo Instituto de Filosofia e Ciências Humanas da Universidade Estadual de Campinas (IFCH/ Unicamp)

2 HANKE, Lewis. The portuguese in Spanish America, with special reference to the Villa Imperial de Potosi. In: Revista de História de América, México, $n^{\circ} 51$, junho, 1961, p. 20.

3 A discussão aqui proposta se insere como um recorte e um desdobramento da pesquisa desenvolvida pela autora durante o mestrado, cujos resultados estão presentes na dissertação: Montanari, Thais. A Capela de São Miguel Arcanjo em São Miguel Paulista: um documento de arquitetura e arte. Dissertação (mestrado) - Universidade Estadual de Campinas, Instituto de Filosofia e Ciências Humanas, Campinas, SP. 2019.

4 Sobre as representações do céu e do inferno na pintura mural andina, Cf. COHEN-APONTE, Ananda. Heaven, Hell, and Everything in Between. Murals of the Colonial Andes. Austin, University of Texas Press, 2016.

5 CORTI et al. La Pintura Mural de Parinacota en el Último Bofedal de la Ruta de la Plata. Arica: Edición de Fundación Altiplano Monseñor Salas Valdés y Centro de Estudios del Patrimonio Universidad Adolfo Ibañez. 2013, p. 27.
} 
Dois estudos publicados em 2018, envolvendo profissionais de diferentes áreas do conhecimento e de diferentes Universidades da Bolívia, Chile e Argentina, analisaram os pigmentos de pinturas murais das igrejas da antiga Ruta de la Plata. O primeiro estudo, "Raman Identification of Pigments in Wall Paintings of the Colonial Period from Bolivian Churches in the Ruta De La Plata. Conservation Science in Cultural Heritage", ${ }^{6}$ analisou pigmentos de quatro igrejas bolivianas dos séculos XVII e XVIII: Curahuara de Carangas, Nuestra Señora de Copacabana de Andamarca, San José de Soracachi, e a sacristia da igreja de Santiago de Callapa. No caso das três primeiras igrejas, o vermelhão (HgS) foi identificado para os pigmentos vermelhos. O segundo estudo, "Characterization of pigments and binders in a mural painting from the Andean church of San Andrés de Pachama (northernmost of Chile)", 7 analisou os pigmentos da igreja de San Andrés de Pachama (século XVIII), na região de Arica-Parinacota, no Chile, e também concluiu que os pigmentos vermelhos desta igreja seriam o vermelhão. Este estudo ainda indica as possíveis fontes de cinábrio de onde se teriam extraído para a produção destes pigmentos: as Minas de Huancavelica, no Peru, as quais já estariam esgotadas no século XVIII, porém podendo também se tratar de outras minas de regiões próximas, como Guamanda, no Peru, e das montanhas de Quíndio, na Colômbia, que também foram exploradas neste período.

Em São Paulo, ainda encontramos o vermelhão nas decorações da Capela de São Miguel Arcanjo, em São Miguel Paulista, ${ }^{8}$ e da igreja Nossa Senhora do Rosário, no Embu. Ambos os templos religiosos surgiram a partir de aldeamentos indígena-jesuíticos entre os séculos XVI e XVII.

O caso da Capela de São Miguel é bastante singular por se tratar de pinturas murais que imitam um altar de talha de estilo nacional-português, as quais permaneceram escondidas embaixo dos altares em madeira, sendo descobertas somente em 2007 durante os trabalhos de restauro da Capela (Figura 1). Este tipo de representação pintada é bastante recorrente na Europa entre os

\footnotetext{
6 RÚA, Carlos et al. Raman Identification of Pigments in Wall Paintings of the Colonial Period from Bolivian Churches in the Ruta De La Plata. Conservation Science in Cultural Heritage, [S.I.], v. 17, p. 117-137, mar. 2018. ISSN 1973-9494. Disponível em: <https://conservation-science.unibo.it/ article/view/7945>. Acesso em: 25 jan. 2019. doi:https://doi.org/10.6092/issn.1973-9494/7945.

7 TOMASINI, Eugenia et al. Characterization of pigments and binders in a mural painting from the Andean church of San Andrés de Pachama (northernmost of Chile), Heritage Science (2018) 6:61. Disponível em: <https://heritagesciencejournal.springeropen.com/articles/10.1186/ s40494-018-0226-x>. Acesso em 25 jan. 2019.

8 Façamos aqui uma correção e um mea culpa: em um dos artigos mais acessados desta autora, apresentado no XII Encontro de História da Arte e publicado nas atas, intitulado "Quatro Séculos de Silêncio: As Pinturas Parietais Da Capela de São Miguel Paulista", é afirmado que os pigmentos das pinturas da Capela de São Miguel seriam "derivados do cal, carvão e ferro". Montanari, Thais. Quatro Séculos de Silêncio: As Pinturas Parietais Da Capela De São Miguel Paulista. In: XII Encontro de História da Arte-Os silêncios na História da Arte, 2017, Campinas, SP, p. 564. Trata-se de uma afirmação errônea, tida a partir de uma informação oral dada por um dos restauradores na ocasião de uma conversa particular e reproduzida pela autora. Ademais, este artigo foi um estudo preliminar sobre a Capela de São Miguel, antes do início do mestrado da autora, e portanto, antes do conhecimento e da análise dos documentos os quais analisam e confirmam que os pigmentos da Capela de São Miguel Arcanjo, são, na verdade, derivados do cal, carbono e uma mistura de vermelho de chumbo e sulfeto de mercúrio.
} 


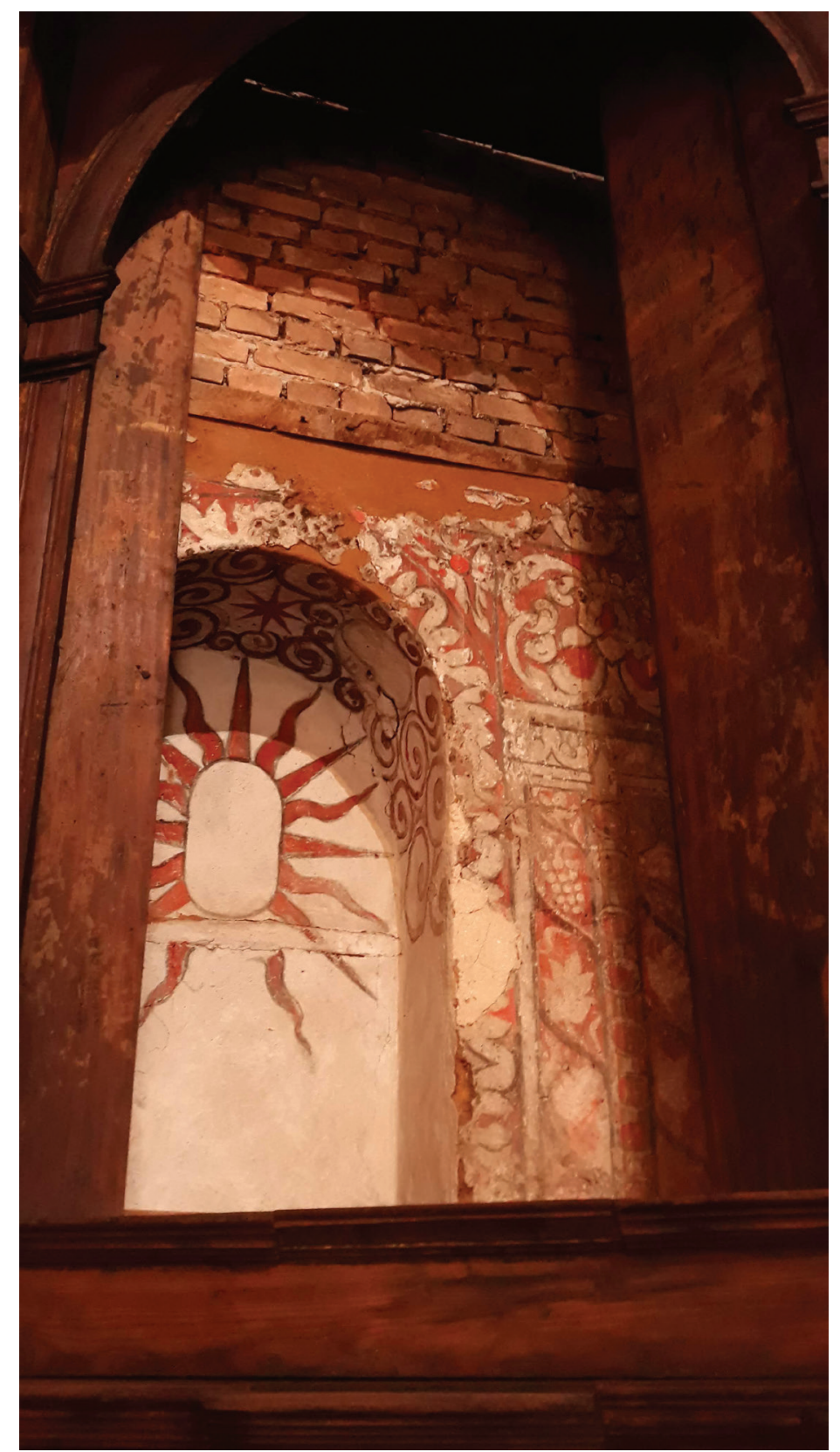

[Figura 1] Pinturas parietais do altar do lado da epístola. Autor(es) Desconhecido(s). Séculos XVII-XVIII. Capela de São Miguel Arcanjo, São Paulo-SP.

Foto: Thais Montanari, abr. 2019. 
séculos XVI e XVIII, especialmente em Portugal, denominados de "retábulos fingidos", e também na Espanha, os "retablos simulados". A mesma prática também foi recorrente na América hispânica, apesar de suas especificidades.

De acordo com o relatório das análises laboratoriais dos pigmentos das pinturas parietais da Capela de São Miguel, concluiu-se que os pigmentos utilizados são derivados principalmente de material mineral, predominando o pigmento vermelho - uma mistura do vermelho de chumbo ( $\left.\mathrm{Pb}_{3} \mathrm{O}_{4}\right)$ e do vermelhão ( $\left.\mathrm{HgS}\right)$. A mesma mistura de pigmentos vermelhos também foram identificados nos altares de talha da igreja de Nossa Senhora do Rosário no Embu (São Paulo), além de outros pigmentos minerais. ${ }^{9}$ Desse modo, além da semelhante estrutura retabular de estilo nacional-português, os retábulos laterais da Igreja Nossa Senhora do Rosário e as pinturas parietais da Capela de São Miguel também possuem os mesmos pigmentos em sua decoração. ${ }^{10}$

A dimensão destas trocas culturais se evidencia pela difusão do uso do vermelhão identificado nas pinturas da Capela de São Miguel, e também nas pinturas murais das capelas da América hispânica da Ruta de la Plata, podendo se estabelecer uma rede entre as duas Américas coloniais. Esta mesma rede seria reforçada pelo comércio entre São Paulo e Paraguai, por meio dos caminhos terrestres ou pelo Atlântico até os portos de Assunção e de Buenos Aires; além da circulação de colonos, indígenas e missionários, que traziam consigo objetos, medicamentos, livros e conhecimento científico. As diversas semelhanças constatadas entre a decoração Capela de São Miguel e de algumas capelas e igrejas da América hispânica e da Europa — tais como o repertório iconográfico do sol, lua e estrelas provenientes de livros de emblemas; o repertório de brutescos e grotescas; a estrutura retabular de estilo nacional-português; e o uso de mão-de-obra indígena e mestiça —; podem demonstrar que São Paulo, ao menos artisticamente, não se encontrava isolada no Planalto.

Outra evidência deste circuito pode ser notada por meio dos inventários dos Colégios Jesuíticos, conforme os estudos de Eliane Fleck e Roberto Poletto. Os autores constataram a presença de mercúrio nos inventários da botica do Colégio Jesuítico de Córdoba, ${ }^{11}$ que contava com aproxima-

\footnotetext{
9 SCHAEFER, Ana Lúcia Pecoraro. Estudos analíticos das técnicas e materiais históricos da Igreja Nossa Senhora do Rosário do Embu - Por um plano de conservação. Tese de Doutorado. Faculdade de Arquitetura e Urbanismo da Universidade de São Paulo, 2000, p. 130-131. 10 Sobre as semelhantes estruturas retabulares entre as pinturas parietais da Capela de São Miguel Arcanjo e outros retábulos paulistas, ver: Montanari, Thais. A Capela de São Miguel Arcanjo e suas pinturas parietais: interculturalidade nas artes das missões jesuíticas no estado de São Paulo. In: CONGRESSO INTERNACIONAL DE AMERICANISTAS, 2018, Salamanca, Memoria Del 56. ${ }^{\circ}$ Congreso Internacional De Americanistas v. 3 Arte. Salamanca: Ediciones Universidad Salamanca, 2018. p. 187-199. Doi: http://dx.doi.org/10.14201/oAQ0251_3. Acesso em: 30 jan. 2019.

11 FLECK, Eliane C. Deckmann; POLETTO, Roberto. "Os colégios e boticas da Companhia de Jesus como centros de formação intelectual e de difusão da cultura científica na América platina setecentista”. In: A Companhia de Jesus na América por seus colégios e fazendas. Organização de Marcia Amantino, Eliane Cristina Deckmann Fleck e Carlos Engemann. Rio de Janeiro: Garamond, 2015, p. 171.
} 
damente $8,260 \mathrm{~kg}$ do elemento puro, e aproximadamente $3 \mathrm{~kg}$ de sulfeto de mercúrio (vermelhão). ${ }^{12}$ Contudo, não sendo possível a análise de inventários do antigo Colégio de São Paulo, temos apenas a hipótese de que o Colégio pode ter sido um receptor deste tipo de material mineral proveniente da América hispânica, difundindo o uso deste pigmento pela vila de São Paulo. Considerando que o Colégio também abrigava as oficinas, a escola onde ensinavam os filhos dos portugueses e os indígenas - estes muitas vezes filhos de portugueses com índias —, a sua riquíssima biblioteca, e a botica, que estava à serviço tanto dos religiosos quanto da comunidade.

De acordo com Gabriela Siracusano, cidades como Cuzco, Potosí e Charcas teriam sido os maiores centros provedores deste tipo de material até o início do século XVIII, evidenciando a circulação de pigmentos minerais e vegetais como resinas, óleos, auripigmento, vermelhão, pau-Brasil, etc., entre as oficinas jesuíticas de Moxos e Chiquitos, ${ }^{13}$ onde estes pigmentos eram processados por aprendizes indígenas se utilizando de pedras ou tacanas. ${ }^{14}$ Assim, é bastante provável que o pigmento vermelho usado na Capela de São Miguel, bem como na igreja de Nossa Senhora do Rosário no Embu, não fossem produzidos localmente, visto que não existem jazidas de cinábrio no Brasil. ${ }^{15}$ Ademais, segundo Siracusano, o uso do vermelhão combinado com o vermelho de chumbo, indicaria que aqueles que decidiram por esta combinação - entre outras - dominavam a práxis e detinham conhecimento especializado, provavelmente advindo da leitura de manuais ou "livros de segredos", e pela troca oral e experimental entre os ofícios que também se utilizavam destas "receitas". Em relação ao vermelhão, é importante ressaltarmos sua utilização e conhecimento pelos ameríndios, entre diversos outros pigmentos. Antes mesmo da colonização, para os indígenas, este derivado do cinábrio era utilizado nas pinturas murais e também corporais, e para a cultura indígena também seria portador de um poder sagrado, e assim como outros minérios, era usado em cerimônias rituais de cura do corpo e da alma.

Ademais, a inserção das oficinas paulistas em redes globais de produção da arte sacra não se limitam ao uso desses pigmentos, haja vista a existência do intercâmbio de um repertório simbó-

\footnotetext{
12 Loc. cit. Também encontrado como marmellón ou bermellón em espanhol.

13 “(...) polvos azules, albayalde, oropimente, resinas, aceites, abalorios de distintos colores llamados chaquiras, bermellón, "colores finos del Perú", 'encomiendas de Cuzco de colores', magno, bol arménico, Palo de Brasil, todos ellos junto a un conjunto de imágenes y lienzos de diferentes advocaciones." SIRACUSANO, Gabriela. El poder de los colores: de lo material a lo simbólico en las prácticas cuturales andinas : siglos XVI-XVIII. Buenos Aires, Argentina: Fondo de Cultura Economica, 2005, p. 107.

14 Ibid., p. 157.

15 O mercúrio não é minerado no Brasil, sendo desconhecida a existência de depósitos. Não sendo um produtor por meio da mineração primária, o Brasil importa toda a quantidade consumida de mercúrio. O cinábrio é abundante no leste europeu, Espanha, México e Argélia. Fonte: Segurança Química- Mercúrio. BRASIL. Ministério do Meio Ambiente. Disponível em: http://www.mma.gov.br/perguntasfrequentes?catid=28. Acesso em: 4 abr. 2018.
} 
lico, modelos e técnicas artísticas as quais mencionamos anteriormente e aprofundamos em nossa dissertação de mestrado. ${ }^{16}$ As pinturas parietais da Capela de São Miguel Arcanjo, por se tratarem de obras necessariamente realizadas in loco - diferentemente, por exemplo, de uma obra de talha que poderia ser realizada em um local e transferida para outro - , e por serem obras realizadas dentro de um contexto específico como o dos aldeamentos indígena-jesuíticos, aparecem como documento de uma relação mediadora entre as culturas europeia e ameríndia.

A partir da análise de elementos muitas vezes considerados como "secundários" na história da arte, como o uso de determinados pigmentos, propomos um novo ol har para o estudo da produção da arte religiosa no contexto da colonização em São Paulo. Dadas as evidências e as possíveis redes apresentadas até aqui, podemos levantar a hipótese de uma ampla rede de artes e ofícios que podem relacionar as regiões de São Paulo e América Hispânica, passando pela região do Rio da Prata até os Andes. O vermelhão, e outros pigmentos minerais, pode ter sido usado na decoração de muitas outras igrejas destas regiões, as quais ainda necessitam de um estudo aprofundado.

\section{Referência bibliográfica}

CAETANO, Joaquim Inácio. "Retábulos fingidos na pintura mural portuguesa". Lisboa: o autor, 2016. p. 1. Disponível em: https://www.academia.edu/21697216/Ret\%C3\%A1bulos_fingidos_na_pintura_mural_portuguesa_vers\%C3\%A30_n\%C3\%A30_publicada_com_todas_as_imagens_dos_ret\%C3\%A1bulos_referidos_. Acesso em: 2 abr. 2018. COHEN-APONTE, Ananda. Decolonizing the Global Renaissance: A View from the Andes. In: SAVOY, Daniel (org.). The Globalization of Renaissance Art. Boston: Brill, 2017.

COHEN-SUAREZ, Ananda. "Painting Beyond the Frame: Religious Murals of Colonial Peru". Collection. In Conversations: An Online Journal of the Center for the Study of Material and Visual Cultures of Religion (2016), doi:10.22332/ con.coll.2016.1.

CORTI, P.; GUZMÁN, F.; PEREIRA, M. La Pintura Mural de Parinacota en el Último Bofedal de la Ruta de la Plata. Arica: Edición 
de Fundación Altiplano Monseñor Salas Valdés y Centro de Estudios del Patrimonio Universidad Adolfo Ibañez, 2013. FLECK, Eliane C. Deckmann; POLETTO, Roberto. "Os colégios e boticas da Companhia de Jesus como centros de formação intelectual e de difusão da cultura científica na América platina setecentista”. In: A Companhia de Jesus na América por seus colégios e fazendas. Organização de Marcia Amantino, Eliane Cristina Deckmann Fleck e Carlos Engemann. Rio de Janeiro: Garamond, 2015. p. 143-181

GERRITSEN, Anne; RIELLO, Giorgio (Ed.). The Global Life of Things. The Material Culture of Connections in the Early Modern World. London / New York: Routledge Taylor \& Francis Croup, 2016.

GISBERT, Teresa. Iconografia y Mítos Indígenas en el Arte (1980). La Paz, Bolívia: Editorial Gisbert \& Cia, 2008.

HANKE, Lewis. The portuguese in Spanish America, with special reference to the Villa Imperial de Potosi. In: Revista de História de América, México, $n^{\circ}$ 51, junho, 1961, p. 1-48.

MARTINS, Renata M. de Almeida. Tintas da terra, tintas do reino: arquitetura e arte nas Missões Jesuíticas do Crão-Pará (1653-1759) [doi:10.11606/T.16.2009.tde-28042010-115311]. São Paulo : Faculdade de Arquitetura e Urbanismo, Universidade de São Paulo, 2009. Tese de Doutorado em História e Fundamentos da Arquitetura e do Urbanismo. [acesso 2019-01-30].

Vestigios cifrados: Destrucción, dispersión y reconstitución del patrimonio jesuítico en los Estados de Rio de Janeiro y São Paulo. H-ART. Revista de historia, teoría y crítica de arte, no 3 (2018): 215-252. http://dx.doi. org/10.25025/hart03.2018.09

MONTANARI, Thais Cristina. A Capela de São Miguel Arcanjo e suas pinturas parietais: interculturalidade nas artes das missões jesuíticas no estado de São Paulo. In: CONGRESSO INTERNACIONAL DE AMERICANISTAS, 2018, Salamanca, Memoria Del 56. ${ }^{\circ}$ Congreso Internacional De Americanistas v. 3 Arte. Salamanca: Ediciones Universidad Salamanca, 2018. p. 187-199. Doi: http://dx.doi.org/10.14201/oAQ0251_3. Acesso em: 30 jan. 2019.

Do Global ao Local: circulação e difusão cultural na decoração da capela do antigo aldeamento de São Miguel Arcanjo (São Paulo séculos XVII-XVIII). In: Eliane Cristina Deckmann Fleck; Jairo Henrique Rogge. (Org.). A Ação Clobal da Companhia de Jesus: Embaixada Política e Mediação Cultural. 1ed. São Leopoldo: Oikos, 2019, p. 713-740.

A Capela de São Miguel Arcanjo em São Miguel Paulista: um documento de arquitetura e arte. Dissertação (mestrado) - Universidade Estadual de Campinas, Instituto de Filosofia e Ciências Humanas, Campinas, SP. 2019.

Vermelhos, Celestes e Mestiços: A Capela de São Miguel Paulista e a difusão cultural entre São Paulo e América Hispânica. In: Martins, Renata Maria de Almeida; Migliaccio, Luciano (Org.). No Embalo da Rede. Trocas Culturais, História e Geografia Artística do Barroco na América Portuguesa. Sevilha / São Paulo: Universo do Barroco Ibero- americano / Universidad Pablo de Olavide / FAU-USP, no prelo.

MONTEIRO, John Manuel. Negros da terra: índios e bandeirantes nas origens de São Paulo. São Paulo, SP: Companhia das Letras, 1994.

RÚA, Carlos et al. "Raman Identification of Pigments in Wall Paintings of the Colonial Period from Bolivian Churches in the Ruta De La Plata". Conservation Science in Cultural Heritage, [S.I.], v. 17, p. 117-137, mar. 2018. ISSN 1973-9494. Disponível em: <https://conservation-science.unibo.it/article/view/7945>. Acesso em: 25 jan. 2019. doi:https://doi. org/10.6092/issn.1973-9494/7945.

SCHAEFER, Ana Lúcia Pecoraro. Estudos analíticos das técnicas e materiais históricos da Igreja Nossa Senhora do Rosário do Embu - Por um plano de conservação. Tese de Doutorado. Faculdade de Arquitetura e Urbanismo da Universidade de São Paulo, 2000.

SILVA, Rodrigo. Sobre Taipas e textos: um estudo sobre as narrativas a respeito da cidade de São Paulo. São Paulo: Alameda, 2013.

SIRACUSANO, Gabriela. El poder de los colores: de lo material a lo simbólico en las prácticas cuturales andinas : siglos XVI-XVIII. Buenos Aires, Argentina: Fondo de Cultura Economica, 2005.

TOMASINI, Eugenia et al. Characterization of pigments and binders in a mural painting from the Andean church of San Andrés de Pachama (northernmost of Chile). Heritage Science (2018) 6:61. Disponível em: <https://heritagesciencejournal.springeropen.com/articles/10.1186/s40494-018-0226-x>. Acesso em 25 jan. 2019. 